parations had values ranging from $2.5 \times 10^{-4} \mathrm{M}$ to $5 \cdot 3 \times 10^{-4} \mathrm{M}$.

2. In the same series of experiments, the inhibitory constant $\left(K_{i}\right)$ of malonate had values ranging from $5.4 \times 10^{-6} \mathrm{M}$ to $9.8 \times 10^{-6} \mathrm{M}$.

3. The ratio of affinities of succinic dehydrogenase for malonate and succinate $\left(K_{m} / K_{i}\right)$, determined directly, varied from $4 \cdot 7$ to 60 , depending on the nature and concentration of the hydrogen acceptor. This variation can be explained by differences in the value of the rate constant $\left(k_{3}^{\prime}\right)$ for the decomposition of the enzyme-substrate complex to give the products of the reaction.

4. The true ratio of affinities of succinic de- hydrogenase for malonate and succinate, in the absence of further reaction of succinate, is about 3.

5. Values of the rate constants of the uninhibited reaction have been calculated, and were found to agree substantially with those previously reported.

6. The results have been briefly discussed in relation to estimates of the ratio of affinities $\left(K_{m} / K_{i}\right)$ by other workers using different types of preparation.

I wish to thank Dr E. C. Slater and Dr W. D. Bonner for kindly allowing me to see a draft of their paper before publication. I am also indebted to Miss J. Perman for valuable technical assistance.

\title{
REFERENCES
}

Ackermann, W. W. \& Potter, V. R. (1949). Proc. Soc. exp. Biol., N.Y., 72, 1.

Bonner, W. D., jun. (1951). Biochem. J. 49, viii.

Briggs, G. E. \& Haldane, J. B. S. (1925). Biochem. J. 19, 338.

Keilin, D. \& Hartree, E. F. (1947). Biochem. J. 41, 500.

Keilin, D. \& Hartree, E. F. (1949). Biochem. J. 44, 205.

Krebs, H. A., Gurin, S. \& Eggleston, L. V. (1952). Biochem. $J .51,614$.

Krebs, H. A. \& Johnson, W. A. (1948). Tabul. biol., Hague, 19, part 3, 100.
Lineweaver, H. \& Burk, D. (1934). J. Amer. chem. Soc. 56, 658.

Potter, V. R. \& DuBois, K. P. (1943). J. gen. Physiol. 26, 391.

Quastel, J. H. \& Wooldridge, W. R. (1928). Biochem. J.22, 689.

Slater, E. C. $(1949 a)$. Biochem. J. 45, 1.

Slater, E. C. $(1949 b)$. Biochem. J. 45, 14.

Slater, E. C. \& Bonner, W. D., jun. (1952). Biochem. J. 52 , 185.

Thorn, M. B. (1953). Biochem. J. 53, i.

Tsou, C. L. (1951). Biochem. J. 49, 512.

\section{The Metabolism of Ethers in the Rabbit}

\section{ANISOLE AND DIPHENYL ETHER}

\author{
BY H. G. BRAY, SYBIL P. JAMES, W. V. THORPE AND MARIE R. WASDELL \\ Department of Physiology, The Medical School, University of Birmingham
}

\section{(Received 11 December 1952)}

Investigations in this laboratory of the metabolic fate of aromatic compounds containing 'potential centres for conjugation' (see Bray, Ryman \& Thorpe, 1948; Thorpe, 1950) have been concerned mainly with compounds containing groups which may be converted to carboxyl in the animal body, e.g. $-\mathrm{CH}_{3} ;-\mathrm{CONH}_{2} ;-\mathrm{CN}$. Another common conjugable group, the hydroxyl group, might theoretically be formed in vivo from ethers. The evidence in the literature suggests that the ether link in unsubstituted alkyl phenyl ethers is not hydrolysed to any appreciable extent in vivo, since Kossel $(1880,1883)$ and Lehmann (1889) found that a glucuronide of ethyl $p$-hydroxyphenyl ether was a major metabolite of phenetole (ethyl phenyl ether) in the dog. With substituted alkyl phenyl ethers, however, there is evidence that considerable dealkylation may occur in vivo, as in the following examples: the formation of $p$-iodophenol from $p$ iodoxyphenyl methyl ether (Röhmann, 1905); of $p$-aminophenol from phenetidine ( $p$-aminophenyl ethyl ether) and phenacetin, its $N$-acetyl derivative (Müller, 1888; Mörner, 1889; Smith \& Williams, $1949 a, b)$; of $p$-hydroxydiphenyl from $p$-methoxydiphenyl and of $p$-hydroxyphenyl $p$-methoxyphenyl ether from di-( $p$-methoxyphenyl) ether (Stroud, 1940a). Stroud did not observe fission of a phenyl group and there appears to be no example in the literature of such fission of diphenyl ethers. It was thus of interest to investigate the metabolism of aromatic ethers in detail. Anisole (methyl phenyl ether) and diphenyl ether have been chosen 
for study as examples of unsubstituted aromatic ethers. The fate of the former does not appear to have been investigated previously, apart from the observation of Coombs \& Hele (1926) that it caused an increased excretion of ethereal sulphate and, so far as we are aware, the only information about the fate of diphenyl ether is the observation of Stroud $(1940 b)$ that, when this ether is injected into rabbits, $23 \%$ is excreted in urine as $p$-hydroxyphenyl phenyl ether and that none of the diphenyl ether is excreted unchanged. In the present investigation the effect of anisole and diphenyl ether on the excretion of ethereal sulphate, glucuronic acid, phenols and mercapturic acid has been determined and the major metabolites isolated and characterized.

\section{MATERIALS AND METHODS}

Materials. Anisole, diphenyl ether and $o$ - and $p$-methoxyphenol were purchased (British Drug Houses Ltd.). The $o$ - and $p$-hydroxyphenyl phenyl ethers used (m.p. $106^{\circ}$ and $82^{\circ}$ respectively) were prepared by the action of potassium phenoxide on $o$ - and $p$-bromophenol in the presence of copper bronze at $180-200^{\circ}$ (Lock, 1930). Di- $(p$-hydroxyphenyl) ether (m.p. $\left.161^{\circ}\right)$ was prepared from di-( $p$-nitrophenyl) ether (Eastman Kodak Co. Ltd.) via di-( $p$-aminophenyl) ether and the corresponding diazonium salt (Häussermann \& Teichmann, 1896; Häussermann \& Bauer, 1897). For the characterization of phenols isolated as metabolites the $p$-nitrobenzyl ethers, carbanilates and phenoxyacetates were prepared as described by Johnson, Shennan \& Reed (1944). The m.p.'s of these derivatives are given in the appropriate sections below. p-Methoxyphenyl p-nitrobenzyl ether forms pale yellow leaflets (m.p. $87^{\circ}$ ). (Found: OMe, 12.1; $\mathrm{C}_{14} \mathrm{H}_{13} \mathrm{O}_{4} \mathrm{~N}$ requires $\mathrm{OMe}, 12.0 \%$.) p-Methoxyphenyl carbanilate forms colourless leaflets (m.p. $133^{\circ}$ ). (Found: $\mathrm{OMe}, 13.0 ; \mathrm{C}_{14} \mathrm{H}_{13} \mathrm{O}_{3} \mathrm{~N}$ requires $\mathrm{OMe}$, $12.8 \%$.)

Animals, diet and dosage. The rabbits used were $2-3 \mathrm{~kg}$. does. They were maintained throughout the experimental period on the diet of pellets and water as previously described (Bray, Ryman \& Thorpe, 1947). The ethers were administered with water by stomach tube at dose levels of $0 \cdot 4-0.5 \mathrm{~g} . / \mathrm{kg}$. No toxic effects were observed.

Analytical methods. Ethereal sulphate was estimated by the gravimetric method of Folin (1905), ether and ester glucuronide by the Shaffer-Hartmann method described previously (Bray, Neale \& Thorpe, 1946), but using 10N$\mathrm{H}_{2} \mathrm{SO}_{4}(0.5$ vol.) for the hydrolysis; glucuronic acid by a modified naphthoresorcinol method (Bray, Humphris, Thorpe, White \& Wood, 1952); and free and total phenols by a modification of the Folin \& Ciocalteu method (Bray, Thorpe \& White, 1950b). Mercapturic acid (iodine consumption after hydrolysis by alkali) was estimated by Stekol's method (1936).

Column chromatography. Fractionation of urine extracts was carried out using a column $(2 \cdot 5 \mathrm{~cm}$. diameter, $60 \mathrm{~cm}$. long) packed with hydrocellulose (Imperial Chemical Industries Ltd.), or powdered Whatman filter tablets, in conjunction with a mechanical fraction collector.

Paper chromatography. The methods were as described by Bray, Thorpe \& White $(1950 a)$. Whatman no. 4 paper was used. The solvent mixtures were: $A$, light petroleum (b.p.
40-60 ${ }^{\circ}$ saturated with formic acid; $B$, light petroleum (b.p. $90^{\circ}$ ) $50 \%$, formic acid $20 \%$, water $30 \%$ (all v/v); $C$, light petroleum (b.p. $90^{\circ}$ ) $48 \%, n$-butanol $4 \%$, formic acid $48 \%$; $D$, light petroleum (b.p. $90^{\circ}$ ) saturated with ammonia (sp.gr. 0.880); $E$, benzene $50 \%$, acetic acid $33 \%$, water $17 \%$. Detection of phenols was most satisfactory with diazotized $p$-nitraniline and $\mathrm{K}_{2} \mathrm{CO}_{3}(20 \%$ w/v) which gave spots with $o-, m$ - and $p$-methoxyphenol which were purple, red and grey-blue with pink edges respectively. In runs of $16 \mathrm{hr}$. $p$-methoxyphenol gave $R_{F} 0 \cdot 33,0 \cdot 24$ and 0.30 in solvent mixtures $A, B$ and $C$ respectively. (Corresponding $R_{F}$ for $m$-methoxyphenol $0 \cdot 4,0.37$ and 0.50 .) No satisfactory solvent mixture was found for guaiacol or its azo dye formed by coupling with diazotized $p$-nitraniline. Both $o$ and $p$-hydroxyphenyl phenyl ethers moved with the solvent front in all solvent mixtures tried. The purple azo dye from $p$-hydroxyphenyl phenyl ether gave $R_{F} 0.6$ when run $1 \mathrm{hr}$. in solvent mixture $D$, but the dye formed from the $o$-isomer did not give satisfactory chromatograms. Di-( $p$-hydroxyphenyl) ether gave $R_{F} 0.6$ (red spot) when run $0.75 \mathrm{hr}$. in solvent mixture $E$, and its azo dye $R_{F} 0.01$ when run $3 \mathrm{hr}$. in solvent mixture $D$.

\section{RESULTS}

\section{Quantitative experiments}

Normal excretion of metabolites. The average daily excretion of ethereal sulphate by individual rabbits ranged from 28 to $55 \mathrm{mg}$. $\mathrm{SO}_{3}$ and the average percentage by which the individual daily normal values differed from the weekly average used for base-line for calculation of final results was $\pm 9 \%$ $\left(3.5 \mathrm{mg} . \mathrm{SO}_{3}\right)$. The corresponding values for reducing material after hydrolysis (expressed as glucuronic acid) were $272-486 \mathrm{mg}$. and $\pm 18 \%$, for glucuronic acid by the naphthoresorcinol method 130-301 mg. and $\pm 8 \%$. For phenols (expressed as and using as standard $p$-methoxyphenol) the values were free $135-173 \mathrm{mg}$. and $\pm 15 \%$, conjugated 31-83 mg. and $\pm 14 \%$; for phenols (expressed as and using as standard $p$-hydroxyphenyl phenyl ether) free $224-279 \mathrm{mg}$. and $\pm 7 \%$, conjugated 116-196 mg. and $\pm 24 \%$.

Metabolites of anisole and diphenyl ether. The quantitative results obtained after administration of the two ethers are summarized in Table 1 . It can be seen that the only metabolites indicated by the analytical results are phenols, excreted either free or as $O$-conjugates and accounting together for approximately $80 \%$ of the dose. The fate of the remainder is unknown. Unchanged ethers were not detected in the urines and no smell of anisole or diphenyl ether was detected in the breath of the animals. There was no significant iodine consumption by alkali-hydrolysed urine, i.e. probably no mercapturic acid formation.

\section{Qualitative experiments}

Anisole. Continuous extraction with ether of urine as collected from rabbits which had each received anisole $(1.5 \mathrm{ml}$.) gave an extract which, 
after evaporation of the solvent, left a syrupy residue in which $p$-methoxyphenol was shown, by paper chromatography, to be the main phenol. Comparison with paper chromatograms of standard $p$-methoxyphenol solutions suggested that not more than $8 \%$ of the dose was present in this form. The $24 \mathrm{hr}$. urine of nine rabbits similarly dosed was hydrolysed by boiling under reflux for $1 \mathrm{hr}$. with hydrochloric acid $(0.2$ vol. $10 \mathrm{~N})$. After cooling it was continuously extracted with ether for $72 \mathrm{hr}$.

\section{Table 1. Amounts of metabolites excreted in urine in $24 \mathrm{hr}$. by rabbits after administration of anisole and of diphenyl ether}

(Dose $0.5 \mathrm{~g} . / \mathrm{kg}$. Results are expressed as percentage of the dose, ranges are given in parentheses and the number of experiments indicated by superior figures.)

\begin{tabular}{lcc}
\multicolumn{1}{c}{ Type of metabolite } & Anisole & Diphenyl ether \\
Ethereal sulphate & $29(24-31)^{3}$ & $12(11-13) 3$ \\
Ether glucuronide & $55(31-65) 6$ & $69(58-76) 6$ \\
Glucuronic acid & $41(35-47)^{6}$ & $57(53-61)^{2}$ \\
Free phenols & $4(1-7)^{4}$ & $15(10-18)^{4}$ \\
Conjugated phenols & $78(76-80) 4$ & $64(55-71)^{4}$ \\
Total phenols by phenol & 82 & 79 \\
estimation & &
\end{tabular}

Total phenols by estimation 81 of conjugating acids and free phenols

The brown syrup left after removal of solvent from the extract was dissolved in acetone and chromatographed, using a paper powder column with benzene as eluent. The 38 hourly portions (approx. $50 \mathrm{ml}$. each) collected were grouped into fractions in which the phenolic constituents were identified by paper chromatography. These fractions, with the hours of collection and the phenols identified, were: $A$, 1-5 hr. no phenols; $B, 6-10 \mathrm{hr}$., $C, 11-15 \mathrm{hr}$., $D$, 16-19 hr. and $E, 20-24 \mathrm{hr}$. $p$-methoxyphenol; $F$, 25-27 hr. $o$ - and $p$-methoxyphenol; $G, 28-38 \mathrm{hr}$. phenols of normal urine including quinol. The amount of quinol found in fraction $G$ corresponded with that found in extracts of hydrolysed normal rabbit urine to which $p$-methoxyphenol had been added, so that the quinol in this fraction can be regarded as that normally excreted by rabbits and not as derived from $p$-methoxyphenol. The phenolic fractions were concentrated under reduced pressure to give syrups, some of which crystallized on standing. Derivatives of methoxyphenol were obtained from these; for example, $B$ (0.5 g.) yielded $p$-methoxyphenyl carbanilate, m.p. $133^{\circ}$ (0.34 g.); $C$ (3.7 g.) $p$-methoxyphenyl-p-nitrobenzyl ether, m.p. $86^{\circ}(2.9 \mathrm{~g}$.$) ; E(0.5 \mathrm{~g}$.) $p$-methoxyphenoxyacetic acid, m.p. $106^{\circ}(0.03$ g.). From fraction $F(0.5 \mathrm{~g}$.$) , which also contained p$-methoxyphenol, a small amount (14 mg.) of $o$-methoxyphenoxyacetic acid, m.p. $117^{\circ}$, was separated.
None of these derivatives depressed the melting point of authentic specimens.

Attempted isolation of a glucuronide. Treatment of the urine by the usual lead precipitation procedure for the isolation of a glucuronide (cf. Bray et al. 1947) gave only a syrup which could not be induced to crystallize. It gave a strongly positive naphthoresorcinol test. An aqueous solution of the syrup, after extraction with benzene to remove unconjugated phenols, was hydrolysed by boiling under reflux with sulphuric acid (equal vol. 10N) for 1.5 hr. and then extracted with ether. The extract was fractionated on a hydrocellulose column, eluting with benzene. $p$-Methoxyphenol was isolated as its $p$-nitrobenzyl ether. A small amount $(6 \mathrm{mg}$. from $8 \mathrm{~g}$. anisole administered) of o-methoxyphenyl $p$-nitrobenzyl ether, m.p. $61^{\circ}$, was also obtained.

Phenol as a metabolite of anisole. It was important to decide whether phenol was a metabolite of anisole in the rabbit. No satisfactory solvent mixture has been found for the identification of phenol by paper chromatography, but mixtures of phenol and $p$-methoxyphenol can be clearly separated on a hydrocellulose column using as solvent a mixture of light petroleum (b.p. 90 (10 vol.), $n$-butanol (1 vol.) and $98 \%$ formic acid, $2 \%$ water (5 vol.). From ether extracts of urine hydrolysed by boiling for $1 \mathrm{hr}$. under reflux with sulphuric acid (equal vol. 10N) separate fractions were collected every $10 \mathrm{~min}$. No unsubstituted phenol was detected in any of the fractions either from normal rabbit urine or from urine collected after administration of anisole. If, however, anisole containing small amounts of phenol was given (purchased specimens of anisole may contain more than $2 \%$ ), some fractions giving a reaction for unsubstituted phenol were obtained. Quantitative estimation of phenol in the combined fractions from such an experiment indicated an amount corresponding to $70 \%$ of that administered which was $27 \mathrm{mg} . / \mathrm{g}$. anisole.

Diphenyl ether. Paper-chromatographic examination of ether extracts of acid-hydrolysed urines from rabbits dosed with diphenyl ether indicated that $p$-hydroxyphenyl phenyl ether was the principal metabolite. Continuous ether extraction (72 hr.) of the pooled $24 \mathrm{hr}$. urines as collected (pH 7.8) from nine rabbits each dosed with diphenyl ether (1 g.) gave an extract from which $p$-hydroxy phenyl phenyl ether (m.p. $\left.80^{\circ}, 30 \mathrm{mg}.\right)$ was obtained. (Mixed m.p. with authentic specimen, $80^{\circ}$.) The residual urine was hydrolysed by boiling under reflux $1 \mathrm{hr}$. with hydrochloric acid $(0 \cdot 2$ vol. $10 \mathrm{~N}$ ) and then continuously extracted with ether for $72 \mathrm{hr}$. An aqueous solution of the ether-soluble material was extracted six times with benzene $(5 \mathrm{ml}$.). The extracts were combined and concen- 
trated under reduced pressure to $15 \mathrm{ml}$. On keeping at $0^{\circ}$ platelets separated (compound $A$ ). Benzene was removed from the mother liquor and the residue recrystallized from water and methanol. $p$-Hydroxyphenyl phenyl ether (m.p. $82^{\circ}$ ) was obtained. (Yield, 1 g.) No o-hydroxyphenyl phenyl ether was detected. Compound $A$ after recrystallization from water had m.p. $156^{\circ}$. (Yield, $8 \mathrm{mg}$.) It reduced ammoniacal silver nitrate and reacted in the same way as di-( $p$-hydroxyphenyl) ether on paper chromatograms. Mixed m.p. with authentic di( $p$-hydroxyphenyl) ether (m.p. $161^{\circ}$ ) 156-160 . (Found: $\mathrm{C}, 70 \cdot 1 ; \mathrm{H}, 5 \cdot 0$. Calc. for $\mathrm{C}_{12} \mathrm{H}_{10} \mathrm{O}_{3}: \mathrm{C}, 71 \cdot 3$; $\mathrm{H}, 5.0 \%$.) Compound $A$ was, therefore, probably impure di-( $p$-hydroxyphenyl) ether.

Phenol could not be detected in the urine by the methods described for anisole urine. The amount of quinol detected by paper chromatograms was no greater than that found in normal rabbit urine.

Isolation of a glucuronide. Application of the lead procedure to urine from rabbits dosed with diphenyl ether gave a syrup which partially crystallized and from which after recrystallization from aqueous ethanol (charcoal) colourless needles, m.p. $174^{\circ}$, were obtained. (Yield, $1.03 \mathrm{~g}$., from $10 \mathrm{~g}$. diphenyl ether.) They gave a strongly positive naphthoresorcinol test and were readily soluble in ethanol, $[\alpha]_{D}^{24^{\circ}}-70^{\circ} \pm 6^{\circ}$ in water $(c, 0 \cdot 172)$. (Found: C, 57.0; H, 5.3; $\mathrm{H}_{2} \mathrm{O}, 4.9 \%$; equiv. wt. 371. pPhenoxyphenyl glucuronide monohydrate, $\mathrm{C}_{18} \mathrm{H}_{18} \mathrm{H}_{8}$. $\mathrm{H}_{2} \mathrm{O}$ requires $\mathrm{C}, 56 \cdot 8 ; \mathrm{H}, 5 \cdot 3 ; \mathrm{H}_{2} \mathrm{O}, 4 \cdot 7 \%$; equiv. wt. 380. $p$-Hydroxyphenyl phenyl ether was isolated from the hydrolysed glucuronide.

\section{DISCUSSION}

From the foregoing experiments it is clear that, in the two unsubstituted ethers examined, fission of the ether linkage in the rabbit does not occur to a significant extent. (The method used for detection of unsubstituted phenol should have revealed an excretion of $3 \mathrm{mg} . / \mathrm{rabbit}$, or fission of $0.3 \%$ of the ether administered.) The chief changes which these compounds undergo in vivo involve the formation of a new centre for conjugation by hydroxylation, with conjugation of the resultant phenolic ethers with glucuronic and sulphuric acids. Over $80 \%$ of the administered compounds can be accounted for in this way. The phenolic ethers formed were predominantly $p$-isomers, small amounts of $o$-isomer being detected only after administration of anisole.
These findings are in accord with those of previous workers on phenetole (Kossel, 1880, 1883; Lehmann, 1889) and on diphenyl ether (Stroud, 1940b). They do not support Williams's (1947) interpretation of the results of Coombs \& Hele (1926) in which he attributes the increased excretion of ethereal sulphate by the dog after ingestion of anisole to conjugation of phenol formed by splitting of the ether linkage. It is clear from our experiments that in the rabbit this ethereal sulphate is almost entirely formed from $p$-hydroxyphenyl methyl ether, and that the $o$-isomer and phenol itself can only contribute to a very small extent. The evidence available suggests that the ether linkage of unsubstituted alkyl phenyl ethers and diphenyl ether is not readily split in vivo in the rabbit and the dog.

A study of the fate of several substituted methyl ethers in the rabbit is in progress in this laboratory and indicates that in some such compounds, e.g. methyl $p$-nitrophenyl ether, extensive fission of the ether linkage, comparable in extent to that found by Stroud (1940a) for di-( $p$-methoxyphenyl) ether and $p$-methoxydiphenyl, may occur. In such compounds the methoxy group may be regarded as a potential centre for conjugation. These experiments will be presented in a later paper.

\section{SUMMARY}

1. The fate of anisole (methyl phenyl ether) and diphenyl ether in the rabbit has been studied.

2. These ethers are hydroxylated and the resultant phenols are excreted unconjugated and conjugated with glucuronic and sulphuric acids to the extent of 2,48 and $29 \%$ of the dose for anisole and 15,63 and $12 \%$ for diphenyl ether respectively.

3. The chief metabolite of anisole is $p$-methoxyphenol but a small amount of $o$-methoxyphenol is also formed. No fission of the ether linkage was detected.

4. The chief metabolite of diphenyl ether is $p$ hydroxyphenyl phenyl ether but a small amount of another metabolite probably di-( $p$-hydroxyphenyl) ether is also formed. No fission of the ether linkage was detected.

\footnotetext{
We are indebted to the Royal Society for a Parliamentary Grant which defrayed part of the expenses of this investigation. The carbon and hydrogen analyses were carried out by Weiler and Strauss, Oxford.
} 


\title{
REFERENCES
}

Bray, H. G., Humphris, B. G., Thorpe, W. V., White, K. \& Wood, P. B. (1952). Biochem. J. 52, 412.

Bray, H. G., Neale, F. C. \& Thorpe, W. V. (1946). Biochem. J. 40, 134.

Bray, H. G., Ryman, B. E. \& Thorpe, W. V. (1947). Biochem. J. 41, 212.

Bray, G. H., Ryman, B. E. \& Thorpe, W. V. (1948). Biochem. J. 43, 561.

Bray, H. G., Thorpe, W. V. \& White, K. (1950a). Biochem. J. 46, 271.

Bray, H. G., Thorpe, W. V. \& White, K. (1950b). Biochem. J. 46, 275.

Coombs, H. I. \& Hele, T. S. (1926). Biochem. J. 20, 606.

Folin, O. (1905). J. biol. Chem. 1, 131.

Häussermann, C. \& Bauer, E. (1897). Ber. dtsch. chem. Ges. 30, 738.

Häussermann, C. \& Teichmann, H. (1896). Ber. dtsch. chem. Ges. 29, 1446.
Johnson, W. C., Shennan, R. S. \& Reed, R. A. (1944). Organic Reagents for Organic Analysis. London: Hopkins and Williams Ltd.

Kossel, A. (1880). Hoppe-Seyl. Z. 4, 296.

Kossel, A. (1883). Hoppe-Seyl. Z. 7, 292.

Lehmann, V. (1889). Hoppe-Seyl. Z. 18, 181.

Lock, G. (1930). Mh. Chem. 55, 184.

Mörner, K. A. H. (1889). Jber. Fortschr. Tierchem. 19, 80.

Müller, F. (1888). Ther. Mh. (Halbmh.) 2, 355.

Röhmann, F. (1905). Biochem. Zbl. 3, 688.

Smith, J. N. \& Williams, R. T. (1949a). Biochem. J. 44, 239.

Smith, J. N. \& Williams, R. T. $(1949 b)$. Biochem. J.44, 250.

Stekol, J. A. (1936). J. biol. Chem. 113, 279.

Stroud, S. W. (1940a). Nature, Lond., 146, 166.

Stroud, S. W. (1940b). J. Endocrin. 2, 55.

Thorpe, W. V. (1950). Brit. Sci. News, 3, 78.

Williams, R. T. (1947). Detoxication Mechanisms, p. 83. London: Chapman and Hall.

\section{The Hydrolysis of Esters of Phenol by Cholinesterases and Other Esterases}

\author{
By L. A. MOUNTER* AND V. P. WHITTAKER \\ Department of Biochemistry, University of Oxford, and Department of Physiology, \\ University of Cincinnati College of Medicine, Cincinnati, Ohio, U.S.A.
}

\section{(Received 24 October 1952)}

In recent years it has been shown that cholinesterases of both types can catalyse the hydrolysis of many non-choline aliphatic esters (for literature see Whittaker, 1951). The primary object of the present investigation was to find out if cholinesterases can also hydrolyse non-choline esters possessing an aromatic nucleus.

A series of $p$-substituted phenyl acetates was selected for study. It was found that these esters are indeed hydrolysed rapidly by the purified cholinesterases of human erythrocytes and plasma and by cobra-venom cholinesterase. During the course of the work it became apparent, however, that, as with aliphatic esters, the hydrolysis of the aromatic esters by whole human erythrocytes and plasma could be accounted for only in part by the cholinesterase content of these preparations. Some additional studies were therefore made of the other esterases involved.

The hydrolysis of aromatic esters by blood and tissues has been the subject of several previous studies, but little attempt has been made to characterize the enzymes responsible for hydrolysing

* Present address: Department of Biochemistry, Virginia University School of Medicine, Charlottesville, Va., U.S.A. them. The hydrolysis of short-chain aliphatic esters of $p$-nitrophenol (Huggins \& Lapides, 1947; Huggins \& Moulton, 1948) and of 2-naphthol (Nachlass \& Seligman, 1949; Seligman, Nachlass \& Mollomo, 1949) was attributed by these authors to aliphatic esterases (ali-esterases). Augustinsson $(1948,1950)$ studied the hydrolysis of acetylsalicylic acid, acetylsalicylylcholine and salicylylcholine by cholinesterase preparations derived from the blood, brain and tissues of various species, but no special precautions were taken to exclude other esterases. Zeller, Fleisher, McNaughton \& Schweppe (1949) showed that preparations of snake venom and erythrocyte cholinesterase free from ali-esterase could hydrolyse phenyl acetate and $p$-nitrophenyl acetate, and that the hydrolysis was fully eserinesensitive, the latter constituting good evidence that the cholinesterase was responsible. Diluted whole human plasma, however, split phenyl acetate very much faster than acetylcholine and the hydrolysis was but little depressed by eserine, a result consistent with that of Huggins \& Lapides (1947) with $p$-nitrophenyl acetate. The hydrolysis of $m$-acetoxyphenyltrimethylammonium methosulphate by human serum and erythrocytes and rat brain was reported by Wescoe, Riker \& Beach (1950). Again, 